\title{
The 'regulated death': a documentary analysis of the regulation and inspection of dying and death in English care homes for older people
}

\author{
KATHERINE FROGGATT*
}

\begin{abstract}
In England, processes of regulation and inspection have been established to ensure that older people living in long-term care settings receive quality care. This paper describes how dying and death in care homes for older people is regulated and inspected. A documentary analysis was undertaken of the standard that addresses dying and death in the 200 I Care Homes for Older People: National Minimum Standards. Present in the standard is a 'good death' template drawn from constructions of best practice in palliative care. The way in which this national standard is enacted in the inspection process is described using a content analysis of the inspection reports from 226 care homes for older people. These present a narrow focus on dying and death, one that emphasises the older person's wishes and the degree of adherence to policies and procedures concerned with the dying and death event. A regulated death attenuates the 'good death' template and reflects both the inspection process and capabilities of the residents of care homes. If the regulation and inspection process is to integrate dying with living, a broader conception and regime of inspection is required. Only then will end-of-life care be provided that meets the diverse needs of older people who live in care homes.
\end{abstract}

$\boldsymbol{K E Y} \boldsymbol{W} \boldsymbol{W} \boldsymbol{R} \boldsymbol{D}$ - older people, care homes, documentary analysis, dying and death, regulation and inspection.

\section{Introduction}

The current processes of external regulation and inspection of care homes for older people in England are examined in this paper, with a focus on the attention that these processes give to the care that the older people who live in these settings receive towards the end of life. Care homes are an important and usually long-term place of care for frail older people (Kerrison and Pollock 200I $a$ ). Institutional nursing and social care for

\footnotetext{
* Institute for Heath Research, Lancaster University.
} 


\section{Katherine Froggatt}

older people in England is predominantly provided outside the public sector. In England in 200I, there were 34I,I75 residential places in care homes that provided personal care, and I4I,9I 6 registered beds for older people in nursing homes (Department of Health 2001 $a$ ).

\section{The English regulation and inspection system}

The Care Standards Act 2000 provides the legislative framework for the regulation of care homes in England. The Commission for Social Care Inspection (CSCI) (formerly the National Care Standards Commission) has the responsibility for the registration and inspection of care homes with reference to the National Minimum Standards for Care Homes (Department of Health 2003 $a$; available online at http://www.dh.gov.uk). Originating in the standards developed by the Centre for Policy on Ageing (1996), these comprise 38 minimum standards in seven main areas: choice of home, health and personal care, daily life and social activities, complaints and protection, environment, staffing, management and administration. There are also cross-cutting themes: a focus on the service user (the term used by the regulatory body to describe those who live in care homes), the need for the care home to be fit for its stated purpose, the comprehensiveness of the care offered, the ability to demonstrate that assessed needs can be met, and that quality services are offered by an adequately experienced and trained workforce. All care homes are registered with CSCI and subject to regular inspections, during which they are assessed against the standards and the supporting regulations, which are enforceable by law. In 2006, each home was inspected twice a year, with one visit being announced and the other unannounced. Over the course of the two inspections, all the standards were to be inspected. Described as a 'command and control' system, a dissonance is apparent between the policy rhetoric of a service-user focus, and the relative low profile of older people as service users in either the regulatory body or the processes of inspection (Kerrison and Pollock 200i $b$ ).

This inspection process was introduced in 2000 and designed to be more 'person-centred' than its predecessor, with more emphasis upon outcomes than inputs (Day, Klein and Redmayne 1996). Each standard is assessed on a four-point scale, ranging from 'not being met' to 'being exceeded'. The written report of the inspection presents a numerical rating and commentary for each standard. Areas of poor performance are identified and time frames stipulated in which to address these aspects of care. One element is to assess the care of three residents against the standards. The inspection reports have several potential uses. They guide care-home managers, proprietors and companies in their work. As the 
reports are in the public domain and posted on the CSCI website, older people and their family members can obtain copies of specific reports to inform their decisions about the choice of a care home. Homes make their own reports available, commonly on a notice board, for the service users and relatives to see. Nationally, the numerical assessment of all care homes for each standard has been collated and provides an overview of the quality of care (Dalley et al. 2004).

\section{Dying and death in care homes}

As well as being places where older people live their lives, care homes are also settings in which they die, with approximately 20 per cent of those who die after 65 years-of-age doing so in such facilities (Office of National Statistics 200I). Increased attention is being paid to the way in which dying and death are managed in care homes in both England (Department of Health 2003 $b$; Froggatt 2004, 2005) and other western countries (Ross, Fisher and MacLean 2000; Australian Government Department of Health and Aging 2004). The provision of palliative care and end-of-life care are variously promoted in care homes as the way to ensure that the residents who are dying receive appropriate care. The understanding of what is meant by these terms, however, varies considerably in English care homes (Froggatt and Payne 2006).

Little research has considered the ways in which policies shape the focus and provision of care along with the management of dying in any care setting. Reviews of Australian policies and standards documents on the care of dying and dead people have shown their influence on care delivery in residential aged-care facilities (O'Connor 2004) and acute hospitals (Quested and Rudge 2003). Despite the mandatory process of regulation and inspection designed to ensure quality care in care homes, a detailed analysis of the operation and focus of the procedures and of their impact on end-of-life care has not previously been undertaken.

\section{Aims, objectives and method}

This study aimed to understand how dying and death was regulated and inspected in care homes for older people in England. It was part of a larger project on the development of end-of-life care in care homes (Froggatt and Payne 2006), and had the following objectives:

- To compare National Minimum Standard i (Dying and Death) with influential palliative-care policy documents. 
- To identify what aspects of Standard II are reported upon by inspectors.

- To identify how inspectors obtain their evidence about Standard II.

The principal research method was document analysis, with a focus on the use of language (Cheek 2004). The text under consideration, Standard I , has two manifestations, first as written in the National Minimum Standards document (Department of Health 2003a), and secondly as reported upon in the inspectors' reports. The National Minimum Standards were taken as a 'generative document' (Prior 2003). The conceptual structures inherent in the standards lay down 'rules' that shape how subsequent inspection reports have been written and constructed. Similarly, the inspection reports shape practice in the care homes, as the managers and provider organisations respond to critical remarks in the reports, although this process is not considered here.

\section{Textual analysis of Standard i I}

Standard II (Dying and Death) is in the 'Health and Personal Care' section of the National Minimum Standards for Care Homes (Department of Health 2003a). After an introductory explanation, the text specifies the required outcome and I2 elements, each of which defines an aspect of care that can be assessed. The foci of the Standard are discussed with reference to the World Health Organisation's (WHO 2002) definition and principles of palliative care, which was selected as having been influential in shaping the provision of palliative care in Britain (National Council for Hospice and Specialist Palliative Care Services 2002; National Institute for Clinical Excellence 2004). The comparison seeks to identify the influences that shaped the generation of the National Minimum Standards on this particular aspect of care.

\section{The management of dying and death in standard II}

Standard I i is concerned with ensuring that service users who are dying receive appropriate care, as is made clear in the introduction: 'The quality of the care which residents receive in their last days is as important as the quality of life which they experience prior to this'. The prescribed outcome focuses on how older people and their family members are treated as the resident dies. The Standard does not differentiate causes of death, and only one disease is specifically mentioned, dementia (paragraph II.9), in a reference to changing care needs. Twelve elements of this Standard are identified that need to be met to achieve the outcome. 
A key theme of the National Minimum Standards, the focus on the service user, is reflected in the Standard. The older person is mentioned in the descriptions of all but one of the elements (II.I2 addresses only policies and procedures). There is great emphasis on the older person's wishes and the authority that he or she holds, specifically with respect to terminal care and arrangements after their death (II.3, iı.8). As well as identifying positive actions, the requirement is that the resident is also able to indicate what he or she does not want to happen, e.g. with respect to who is involved in plans about their care (II.4) or who is present as they die (II.IO). The role of older people in the care of another dying resident is also acknowledged (I I.7).

The roles of family and friends, the care staff, the 'registered person' (who is accountable for the care home to the registration body and is usually the care-home manager), and external health-care and social-care professionals are also referred to. The need for family and friends to be involved and present are recognised (Introduction, Outcome, II.4, I I.IO, II.II), but their access depends on the preferences of the older person (II.4, II.Io). Care staff are seen as the givers of care (Introduction, Outcome, II.2, II.7 and II.I2), and the role of the registered person is to ensure appropriate support for the care staff (II.7). External health-care and social-care professionals are mentioned, either as specialists in the care of dying and bereaved people, as with Macmillan and Marie Curie nurses (Introduction), or as specialist palliative-care professionals or specialist agencies (II.IO). The Introduction has many references to the diverse care that is to be provided to meet individual identified needs, and more specific references follow, to issues of care for physical needs (II.I, II.2, II.3, II.9), emotional needs (II.7), spiritual needs (II.I) and cultural needs (II.I). The only specific physical-care issue mentioned is pain and its management (I I.2). Issues of dignity (I I.I, I I.5), propriety (I I.I) and privacy (I I.5) are also specifically mentioned.

A comparison of Standard I I with the WHO Principles of Palliative Care finds several important similarities (Table I). Both documents feature meeting the physical, psychological and spiritual needs of both service users and their family members, and both underline the importance of different professionals working together, either as an in-house team or by bringing specialist expertise into the care home. There are, however, also differences. Dying is considered a normal process in the WHO principles, but in the National Minimum Standards, in contrast, it 'must never be regarded as routine'. There is also no mention in the Standards of the balance to be kept between life and death, as prescribed in the WHO principles, which state that death is to be 'neither hastened nor postponed'. The time-frame for palliative care is much longer in the WHO 
T A B L E I. Comparison of United Kingdom Standard II with the WHO principles of palliative care

\begin{tabular}{|c|c|c|}
\hline WHO principles of palliative care ${ }^{1}$ & In Introduction to Standard II $^{2}$ & In Standard I i elements ${ }^{2}$ \\
\hline $\begin{array}{l}\text { Provides relief from pain and other } \\
\text { distressing symptoms }\end{array}$ & Pain and distress should be controlled & $\begin{array}{l}\text { II.I Care and comfort; iI.2 Appropriate attention } \\
\text { and pain relief }\end{array}$ \\
\hline $\begin{array}{l}\text { Affirms life and regards dying as a normal } \\
\text { process }\end{array}$ & $\begin{array}{l}\text { The process of dying and death itself must never be } \\
\text { regarded as routine by managers and staff. }\end{array}$ & II.6 Remaining in own room \\
\hline
\end{tabular}

Intends neither to hasten or postpone deat
Integrates the psychological and spiritual

aspects of care

Offers a support system to help patients live as actively as possible until death

Offers a support system to help the family cope during the patient's illness and in their own bereavement

Use a team approach to address the needs of patients and their families, including bereavement counselling, if indicated

Will enhance quality of life and may also positively influence the course of illness Applicable early in the course of the illness
(The resident's) physical and emotional needs must be met, their comfort and well-being attended to, and their wishes respected.

Opportunities for meditation and reflection and for contact with local and religious spiritual leaders should be provided.

Cultural and religious preferences must be observed.

Residents should be encouraged to express their wishes about what they want to happen when death approaches and to provide instructions about

the formalities to be observed after they have died.

The needs of family and friends should be attended to.

The professional skills of palliative care staff can help homes ensure the comfort of residents who are dying.

There are a number of specialist agencies providing practical assistance and advice, such as Marie Curie and Macmillan nurses, which can be called upon.
II.I Spiritual needs

I I. 3 Meeting service user's wishes

II.4 Involvement of family and friends; II.Io Family and friends being with the service user; II.I I Family paying respects

I I.8 Involvement of specialist agencies (palliative care, bereavement)

I I.9 Meeting changing needs of the service user

Notes: I. World Health Organisation 2002. 2. Department of Health $2003 a$. 
principles, where its applicability at an earlier stage of illness is recognised, although Standard II recognises the process of deterioration (II.9). The WHO principles do not specifically mention the death event, and the Standard only refers to aspects of care for the body when attention is paid to the wider structural, cultural and staffing issues of the care setting. The need for policies and procedures to create a culture of openness in which dying and death can be talked about, and for staff education, are all specified. Although not addressed in the WHO document, staff education is addressed in related UK palliative-care policy documents (National Council for Hospice and Specialist Palliative Care Services 2002; National Institute for Clinical Excellence 2004). It is against this Standard that the inspectors assess care homes and their provision of end-of-life care.

\section{Content analysis of a sample of inspection reports}

To examine how Standard I I was assessed and reported by the statutoryagency inspectors, a content analysis was undertaken of the written feedback in their reports (Silverman I993). The analysis particularly examined which aspects of Standard I I were reported upon and what evidence was drawn upon in the assessment. The inspection reports for all 265 care homes in South Yorkshire that were issued between April 2002 and December 2003 by the then National Care Standards Commission were analysed. The reports are in the public domain and were downloaded from the website (www.ncsc.gov.uk). There were 485 inspection reports from the 265 care homes, but of these I 33 provided no information about Standard iI. The analysis was therefore of $35^{2}$ reports from 226 care homes. The text of the inspection reports was entered into the $\mathcal{N}$-Vivo qualitative data analysis package, and the content coded according to the I2 elements of Standard Ir. Any information in the report on Standard I I that indicated from whom or how the evidence was obtained was also coded.

\section{The regulated death}

It was found that the reports focused upon particular aspects of the dying and death standard, most apparently the presence of appropriate policies and procedures (paragraph II.I2) and evidence that service users' wishes had been met (II.3), which was reported in over 75 per cent of the reports (Table 2). Other elements of the Standard that were mentioned in more than $5^{\circ}$ per cent of the reports were: attention to pain relief (II.2), the involvement of specialist agencies (II.8), and the presence of family and 
T A B L E 2. The coverage of the elements of Standard II in the inspection reports

\begin{tabular}{llcc}
\hline & & \multicolumn{2}{c}{ Inspection reports } \\
\cline { 3 - 4 } Element & \multicolumn{1}{c}{ Focus of element } & Number & Per cent \\
\cline { 2 - 3 } II.I & How dying is handled; spiritual needs & I72 & 48.9 \\
II.2 & Pain relief & 2 I2 & 60.2 \\
II.3 & Meeting service user's wishes & 277 & 78.7 \\
II.4 & Involvement of family and friends & I4I & 40.1 \\
II.5 & Maintaining privacy and dignity & I35 & 38.5 \\
II.6 & Place of death & 36 & I0.2 \\
II.7 & Staff and service-users enabled to support & II3 & 32.1 \\
& $\quad$ dying service-users & & \\
II.8 & Involvement of specialist agencies & 203 & 57.7 \\
& (palliative care, bereavement) & & \\
II.9 & Meeting changing needs of the service-user & 27 & 7.6 \\
II.IO & Family and friends being with the service-user & 220 & 62.5 \\
II.II & Handling the body and paying respects & 4 & I.I \\
II.I2 & Policies and procedures & 283 & 80.4 \\
\hline
\end{tabular}

friends with the service-user who was dying (II.Io). Although the involvement of specialist agencies (II.8) was mentioned in $5^{8}$ per cent of the reports, specific mention of specialist palliative-care services occurred in only I2 per cent, the other named specialist professionals being GPs and district nurses. The least mentioned elements of the Standard were those that focused on the two extremes of the dying process, the actual death event (II.II), and long-term changes in a person's condition prior to death that indicated increasing frailty and deterioration (I I.9).

The evidence for the inspection was collected through both consultation and observation (Table 3). The inspectors consulted owners, managers, residents, relatives, friends and staff. Reports of discussions with staff were most frequent (62\% of reports). Retrospective discussions of particular cases were used by the inspectors to assess the knowledge and skills of the home's staff. The residents were consulted about Standard II in only Ig inspections $(5.4 \%)$. Where they were consulted, the focus was on their own care needs, the extent to which their wishes for terminal care and funeral arrangements had been ascertained, and their observations of other residents' care. In a few instances, in-depth conversations were reported, e.g. 'a service-user who had recently lost her husband provided clarification on how staff supported a terminal ill service-user and their family'.

The other key source of evidence, observation, involved both direct observations of care and indirect observations through the evaluation of written care-plans, other documents and policies and procedures. If, on the day of the inspection, a resident was terminally ill or dying, then 
T A B L E 3. Sources of evidence reported by inspectors to assess Standard II

\begin{tabular}{lcr}
\hline & \multicolumn{2}{c}{ Inspection reports } \\
\cline { 2 - 3 } Source of evidence & Number & Per cent \\
\hline Consultation with: & 79 & \\
$\quad$ Relatives & 19 & 22.4 \\
Residents & 217 & $6 \cdot 4$ \\
Staff & 93 & 26.4 \\
Manager & 8 & 2.3 \\
Friends & 3 & 0.8 \\
Owner & & \\
Observation of: & 24 & 6.8 \\
Policies & 235 & 66.8 \\
Care plans & $\mathrm{I}$ & 0.2 \\
Letters from relatives & 3 & 0.8 \\
Staff files & 352 & I0.. \\
Number of inspection reports & & \\
\end{tabular}

the inspector drew upon that experience to make an assessment: this occurred in $16(5 \%)$ inspections. In one case, for example, 'the inspector observed staff offering care and comfort to service-users suffering terminal illness. Staff were observed ensuring that these service users were encouraged to eat a little, that they were warm, and that they could retire to their rooms with some help when they wanted. Staff and management were observed consulting relatives and health professionals such as Macmillan nurses.'

In two inspection reports it was stated that the Standard was not assessed because no resident was dying or terminally ill at the time. Documentation was frequently an important source of observable evidence, and its appraisal was reported in two-thirds of the reports (Table 3). Care-plans were looked at to ascertain whether the resident's wishes had been recorded, specifically their wishes regarding terminal care, funeral arrangements, dying and death, and religious preferences. Staff files were used to find evidence of staff training with respect to care for dying residents.

\section{Implications of a regulated ' $g o o d$ death'}

This analysis of the regulation and inspection of dying and death in care homes indicates that the regulations have similar values to those found in mainstream palliative-care directives. What is presented in Standard I I is a particular construction of a 'good death'. The term a 'good death', Kalos thanatos in Greek, means a beautiful death or the ideal or exemplary 


\section{Katherine Froggatt}

death (Kellehear I990). The good death comprises various culturallysanctioned and prescribed behaviours that seek to control the unpredictable nature of biological death. The good death provides a framework for locating an individual's experience of something which cannot be rehearsed or practised. Conceptions of the ideal good death have changed through history and reflect wider social norms. Whilst various 'good deaths' are prescribed in contemporary society (Komaromy, Sidell and Katz 2000), most emphasise the autonomy and control that currently are strongly held 'western' values, while the hospice and palliative-care movement has been very influential in promoting particular templates for dying (Walters 2004). The palliative-care 'good' death is one of an open awareness of dying, good and open communication, the acceptance of death, settling one's business, and the relief of suffering (McNamara 2004). Similar features are seen in Standard ir. The Dying and Death Standard provides a framework that explicitly and implicitly shapes the care provided in care homes for dying residents, but because Standard II was derived from and is positioned in the context of the National Minimum Standards, particular emphasis is placed upon the service-user and their autonomy and control.

The inspection of the management of dying and death in care homes for older people focuses mainly upon easily measured aspects of care, particularly the written record of the resident's wishes and visible policies and procedures. This reflects both the attributes of care identified in the Standard and the process of inspection. Less attention is paid to the aspects of the Standard that cannot be so easily captured or that address long-term issues, such as deterioration and changing needs. The way in which the Standard is reported reflects three inter-related factors: first, the practicalities of undertaking the inspections; secondly, the diverse range of health and social-care needs of the residents; and thirdly, the changing nature of their needs over time. Although Standard II promotes the service-user being in control, having choices and expressing wishes, it is difficult to ascertain if this has been the case. It is not usually appropriate to ascertain directly from residents who are close to death if their needs and wishes have been and are being met, even those who are physically well enough to communicate with an inspector. A large proportion of the older residents of care homes have some cognitive impairment (Matthews and Dening 2002), which makes communication between inspectors and residents difficult. Problems with communication may also be an issue for staff as they seek to ascertain a person's wishes about end-of-life care and support. Family members may provide proxy accounts of the extent to which a resident's wishes have been met and about the quality of care, but ascertaining these views when someone is dying is again not always 
appropriate. Hence, to make judgements about the quality of care that a resident has received, the inspectors rely on documentation and on retrospective and prospective accounts.

The structure of the inspection process constrains the inspectors' ability to draw conclusions about the quality of care towards the end of life. During an inspection, inspectors are required to address in one day many aspects of care-home life. Dying and death are not necessarily perceived as the most important foci of care. The inspectors can only assess the care delivered that day, and only observe what is there to be seen; death cannot be planned for. If a death occurred during the inspection visit, then inspectors clearly drew upon their observations of the event. Similarly, if a resident was deemed to be dying, then this was used to draw conclusions about the standard of care provided.

A particular understanding of the nature of dying and death is apparent in the inspection reports. The emphasis is upon the event of death or on the period immediately before the death, when it was 'known' that an individual was dying. If no resident met the inspector's criteria for 'dying', then sometimes Standard I I was not assessed. This narrow understanding of dying, as being the period just before an individual's death, reflects the focus of the Standard. Death is conceived and described as a clearly definable event around which care can be directed. This interpretation and the practical constraints of inspection lead to the limited assessment of the Standard.

A broader understanding of dying and of the end-of-life period is present in Standard I I, but only implicitly, for element I I.9 focuses on the changing needs of a service-user who has a deteriorating condition or dementia. This temporal dimension is however framed in the context of maximising an individual's control and ability, and with expressions of the consensus (in policy documents) of the desirability of promoting 'healthy ageing' (Reed et al. 2003). English policy directives encourage rehabilitation and intermediate-care services for older people in care homes (Department of Health 200I b). The consequence is that dying and its management is not central to care-home activity. The relationship between ageing and dying is problematic and particularly contested in care homes (Hockey I990; Froggatt 200i; Lloyd 2004). The emphasis on dying and death as being something that 'must never be regarded as routine' segregates this care as a different type of work.

This study has identified some important, but often hidden, issues about long-term residential care for older people. Whilst it has been shown that British long-term care nursing staff are overwhelmed by policy initiatives (Tolson et al. 2005), this study has examined the direct interventions and regulation of the National Minimum Care Standards and the CSCI inspections. 


\section{Katherine Froggatt}

The purpose of the regulation and inspection process is to ensure highquality care: the rationale is that deficiencies in care will be identified, and actions prescribed to correct them. Identifying which aspects of care are emphasised, and which comparatively neglected, develops our understanding of where care-home managers are directed to focus their attention.

\section{Limitations and reflections}

The limitations of this analysis of Standard I I and its use in the inspection process are that it has focused on only one aspect of care. Aspects of the care of a dying resident and of the management of their death may be addressed by other Standards. Nor has this analysis addressed the impact of the inspections on the care experienced by residents and their families. Nonetheless, important questions have been raised about the process of inspection, and how this may shape the way in which the National Minimum Standards are applied and acted upon. Important implications for the delivery of care and consequently on the experience of living in care homes have been shown, particularly in the sensitive area of end-of-life care.

More research is required in this area to examine all 38 Standards and to gain a full picture of the ways in which discourses of dying and death are present and addressed by the Standards and then interpreted in the inspection process. It would also be useful to explore the regulation and inspection process from the inspectors' perspectives. While these can be detected in the inspection reports, they are not always readily identifiable and have not been analysed in this study. An understanding of the ways in which the inspectors work, their backgrounds and knowledge would be informative. Variations in the standard of inspections have been linked to the variable experience of the staff (Day, Klein and Redmayne I996). Similarly, it would be useful to know more about the care-home managers' and staff's attitudes and reactions to the process, and about the extent to which the inspections influence their work and are an agent of change. In what ways do they improve the quality of care experienced by service users?

Comparative research on comparable regulation and inspection systems in other countries would identify different influences on the long-term provision of care of frail older people. The national (English) system described here differs from the systems devolved to the States in the United States (Harrington 200I), and to the States and Territories in Australia (Braithwaite 200I). Even in the United Kingdom, differences between the four historic nations can be seen. In Scotland, for example, 
national general palliative-care practice statements for care homes have been developed to support the regulation and inspection process.

\section{Conclusions}

This paper has been written as the British inspection and regulation bodies are changing. In England, a consultation review of the Standards and inspection process is underway, and changes will be implemented late in 2006. CSCI is to merge with The Health Commission (the body that currently regulates and inspects all health-care providers) to bring all regulation and inspection agencies into one body. The extent to which these changes will affect the inspection is of course not known. It is likely that the same personnel, with their particular understanding of dying and death, will continue to undertake the inspections, which might suggest that their influence will remain the same. It is believed that there has been a narrow focus on dying and death in the regulation and inspection process, and that this limits the provision of end-of-life care to older people who live in care homes. The development of a broader view of end-of-life care in the Standards, and its integration into the everyday life and work of care homes, would enhance the quality and outcomes of care. An understanding that all care in care-homes is end-of-life care would free inspectors from having to determine if a service-user was imminently dying before believing that they can assess the quality of care with respect to Standard II. The standards of care outlined here are applicable regardless of whether an individual is known to be dying or not. The challenge is to find ways to work with this different approach within the constraints of both the current inspection process and carehome practice.

\section{Acknowledgements}

This study was undertaken as part of a post-doctoral research fellowship funded by The Health Foundation.

\section{References}

Australian Government Department of Health and Aging 2004. Guidelines for a Palliative Approach in Residential Aged Care. Rural Health and Palliative Care Branch, Australian Government Department of Health and Aging, Canberra.

Braithwaite, J. 200I. The challenge of regulating care for older people in Australia. British Medical fournal, 323, 7310, 443-6. 


\section{Katherine Froggatt}

Centre for Policy on Ageing 1996. A Better Home Life: A Code of Practice for Residential and Nursing Home Care. Centre for Policy on Ageing, London.

Cheek, J. 2004. At the margins? Discourse analysis and qualitative research. Qualitative Health Research, 14, 8, I $4_{40}^{-50}$.

Dalley, G., Unsworth, L., Keightley, D., Waller, M., Davies, T. and Morton, R. 2004. How Do We Care? The Availability of Registered Care Homes and Children's Homes in England and Their Performance Against National Minimum Standards 2002-03. Stationery Office, London.

Day, P., Klein, R. and Redmayne, S. 1996. Regulating Residential Care for Elderly People. Social Care Research Paper 78, Joseph Rowntree Foundation, York.

Department of Health 200I $a$. Community Care Statistics 200I. Department of Health, London.

Department of Health 200 $b$. National Service Framework for Older People. Department of Health, London.

Department of Health 2003a. Care Homes for Older People: National Minimum Standards. Stationery Office, London.

Department of Health 2003 b. Building on the Best: Choice, Responsiveness and Equity in the NHS. Stationery Office, London.

Froggatt, K. 200I. Life and death in English nursing homes: sequestration or transition? Ageing \& Society, 2 I, 3, 319-32.

Froggatt, K. 2004. Palliative Care in Care Homes for Older People. National Council for Palliative Care, London.

Froggatt, K. 2005. 'Choice over care at the end of life': implications of the End-of-life Care Initiative for older people in care homes. Fournal of Research in Nursing, 10, 2, I89-202.

Froggatt, K. and Payne, S. 2006. A survey of end-of-life care in care homes: issues of definition and practice. Health and Social Care in the Community, 14, 4, 341-8.

Harrington, G. 200r. Residential nursing facilities in the United States. British Medical fournal, 323, 731 1 , 507-IO.

Hockey, J. I99o. Experiences of Death: An Anthropological Account. Edinburgh University Press, Edinburgh.

Kellehear, A. I990. Dying of Cancer: The Final Year of Life. Harwood Academic Publishers, London.

Kerrison, S. and Pollock, A. 200i $a$. Caring for older people in the private sector in England. British Medical Journal, 323, 7312, 566-9.

Kerrison, S. and Pollock, A. 200 $b$. Absent voices compromise the effectiveness of nursinghome regulation: a critique of regulatory reform in the UK nursing-home industry. Health and Social Care in the Community, 9, 6, 490-4.

Komaromy, C., Sidell, M. and Katz, J. 200o. The quality of terminal care in residential and nursing homes. International Fournal of Palliative Nursing, 6, 4, 192-200.

Lloyd, L. 2004. Mortality and morality: ageing and the ethics of care. Ageing \& Society, 24, $2,235-56$.

Matthews, F. and Dening, T. 2002. Prevalence of dementia in institutional care. The Lancet, 36o, 9328, 225-6.

McNamara, B. 2004. Good enough death: autonomy and choice in Australia palliative care. Social Science \& Medicine, 58, 929-38.

National Council for Hospice and Specialist Palliative Care Services 2002. Definitions of Supportive and Palliative Care. National Council for Hospice and Specialist Palliative Care Services, London.

National Institute for Clinical Excellence 2004. Guidance on Cancer Services: Improving Supportive and Palliative Care for People with Cancer. National Institute for Clinical Excellence, London. 
O'Connor, M. 2004. What do residential aged-care facility policies say about palliative care and dying? Collegian, I I, I, 27-3I.

Office of National Statistics 2001. Community Care Statistics 200o. Stationery Office, London.

Prior, L. 2003. Using Documents in Social Research. Sage, London.

Quested, B. and Rudge, T. 2003. Nursing care of dead bodies: a discursive analysis of last offices. Fournal of Advanced Nursing, 4I , 6, 553-6o.

Reed, J., Cook, G., Childs, S. and Hall, A. 2003. Getting Old is for Cowards: Comfortable, Healthy Ageing. Joseph Rowntree Foundation, York.

Ross, M., Fisher, R. and MacLean, M. 2000. A Guide to End-of-Life Care for Seniors. Health Canada, Ottawa.

Silverman, D. 1993. Interpreting Qualitative Data. Sage, London.

Tolson, D., Maclaren, W., Kiely, S. and Lowndes, A. 2005. Influence of policies on nursing practice in long-term care environments for older people. Fournal of Advanced Nursing, 50, 6, 66I-7I.

Walters, G. 2004. Is there such a thing as a good death? Palliative Medicine, 18, 5, 404-8.

World Health Organisation 2002. National Cancer Control Programmes: Policies and Guidelines. WHO, Geneva.

Address for correspondence:

Accepted 3 I Fuly 2006

Katherine Froggatt, Institute for Health Research, Lancaster University, Lancaster LAi 4YW, United Kingdom.

E-mail: k.froggatt@lancaster.ac.uk 